\title{
Academic Related Variables and Attitudes toward Substance Abuse among Secondary School Adolescents in Barbados
}

\author{
Grace A. Fayombo \\ School of Education, Faculty of Humanities and Education, \\ The University of the West Indies, Cave Hill Campus \\ BB11000, Barbados. \\ Tel: +1246-246-257-3998 or +1246-246-417-4435 \\ E-mail: grace.fayombo@cavehill.uwi.edu
}

Received: April 4, 2011 Accepted: April 13, 2011 doi:10.5430/wje.v1n1p136

This research was supported with the Study and Travel Grant, The University of the West Indies, Cave Hill Campus, under Project No. 2009/2010 session.

\begin{abstract}
This study investigated the relationships between some academic related variables (interest in school, psychological resilience, study habit) and attitudes toward substance abuse among $220(M=15.1, S D=1.10)$ secondary school adolescents in Barbados. Results revealed that interest in school, psychological resilience and study habits negatively correlated with adolescents' attitudes toward substance abuse. The academic related variables also jointly contributed $45 \%$ ( $\mathrm{R}$ Square $=0.445$ ) of the variance being accounted for in attitudes to substance abuse and this was found to be statistically significant $(\mathrm{F}(3,216)=57.63, \mathrm{p}<.0005)$. Additionally, it was found that interest in school was the best predictor of attitudes to substance abuse and that psychological resilience and study habit were other significant predictors. These results were discussed in the light of the importance of these academic variables preventing adolescents' substance abuse.
\end{abstract}

Keywords: Substance abuse, Adolescent, Attitude, Interest in school, Psychological resilience, Study habit, Risk factors, Protective factors

\section{Introduction}

Evidence suggests that the key risk periods for substance abuse occur during major transitions in children's lives and that they are already taking alcohol and abusing substances such as heroin, cocaine, marijuana, alcohol, amphetamine, $\mathrm{LSD}_{25}$ at age 10 or younger. Moore, Rothwell, and Segrott (2010) found prevalence consumption of alcohol among secondary school adolescents aged 11-16 years in Wales; National Survey on Drug Use \& Health (2009) also reported prevalence of substance abuse, serious mental illness, related problems, and treatment among selected sample of 12 year old or older in the United States. Similarly, Vaughn, Ollie, McMillen, Scott, and Munson (2007) found prevalence use of various substances (especially marijuana) among 17-year old youths in Missouri State, while Zoccolillo. Vitaro, and Tremblay (1999) reported illegal use of drugs among a sample of adolescents with mean age 15 years in the province of Québec, Canada and similar prevalence was also reported among the Nigerian adolescents (Fayombo, 1999).

The grave consequences of substance abuse reported were that there was prevalence of substance use disorders (SUDs) among adolescents who received services in public sectors of care in San Diego (Aarons, Brown, Hough, Garland, \& Wood 2001) and that adolescent cannabis users had high rates of psychiatric disorders in Baltimore (Subramaniam, Stitzer, Woody, Fishman, \& Kolodner, 2009). Investigators therefore proposed some reasons for adolescents' vulnerability to substance abuse. For instance, Gogtay et al. (2004) in their study of brain development among the United State adolescents attributed this to the fact that the brain areas (prefrontal cortex) for assessing situations, making sound decisions and keeping the emotions and desires under control are still maturing during adolescence thereby putting them at increased risk for poor decisions. Luo, Urberg and Fang (1999) also found that across cultures, among the European American, African American, and Chinese adolescents, drug use was highly associated with high sensation seeking and low authoritative parenting. 


\section{Substance Abuse among the Caribbean Adolescents}

In the Caribbean, Maharaj, Nunes, and Renwick, (2009) reported lifetime prevalence of substance abuse among the adolescents. Similarly, a survey of 2,220 secondary school students in Barbados revealed lifetime prevalence of cigarette smoking among $21.3 \%$ of the sample, use of alcoholic beverages around 10.9 years, inhaling solvents by 10.4 years, marijuana use by 12.6 years and lifetime prevalence for other drugs like heroin, opium, morphine, hallucinogens and hashish (National Council for Substance Abuse 2006). Additionally, there were reports that young males regarded drinking alcohol and ganja smoking as a "rite of passage" rather than substance abuse (Caribbean Research Crucial to tackling Regional Drug Abuse 2005). Researchers have pointed out the similarities in the prevalence of risk factors among adolescents in the United States and the Caribbean that there were high reported levels of lifetime use of alcohol (74\%), marijuana (38\%) and cocaine (8\%) in the US compared with the average Caribbean data of 52\%, $17 \%$ and $2 \%$ respectively (Blue \& Ireland 2004; Douglas \& Fountain, 2004; Kurtz, Douglas, \& Lugo, 2005).

Researchers also identified factors associated with greater potential for substance abuse as risk factors, which include early aggressive behavior, academic failure, poor social skills, lack of parental supervision, drug availability and poverty. Those associated with reduced potential for substance use are protective factors including self-control, academic competence, positive relationships, parental monitoring and support and anti-drug use policies (National Institute on Drug Abuse, 2003). Literature also suggests that youths who rapidly increase their substance abuse have high levels of risk factors with low levels of protective factors, the more risks a child is exposed to, the more likely the child will abuse drugs (Dishion et al. 2002). In order to reduce the potential for substance abuse, an important goal of prevention is to change the balance between risk and protective factors so that protective factors outweigh risk factors (The National Institute on Drug Abuse 2003).

This research therefore focuses on the academic related variables that may enhance academic performance which are likely to protect and prevent adolescents from substance abuse: interest in school, psychological resilience and study habits.

\section{Interest in School}

Evidence abounds that interest in schooling predicted academic self efficacy, science achievement and academic achievement among the Nigerian secondary school students; (Olatoye \& Ogunkola 2008). The National Household Survey on Drug Abuse (2003) reported that United State adolescents aged 12 to 17 who enjoyed going to school, who felt that their assigned schoolwork was meaningful, or who felt that the things they learned in school were going to be important later in life were less likely to have used illicit drugs or alcohol compared with youths who did not have these positive attitudes toward school and that poor school satisfaction was significantly associated with cannabis use among the Danish adolescent sample (Hoff, Anderson \& Holstein 2010).

\section{Psychological Resilience}

Literature suggests that psychological resilience indicates adaptive coping, adversity quotient and emotional intelligence (Goleman 2006). Bauer, Keefe, and Shea, (2001) found that adolescents who experience specific learning difficulties frequently exhibit few protective factors and struggle to adapt successfully when confronted by difficulty and their inherent strengths or resilience skills are frequently lacking (Donald, Lazarus, \& Lolwana, 2002). In addition, Karatzias, Power, and Swanson (2001) found that among Scottish adolescents, school stress was the factor that most accurately predicted a student's likelihood to try alcohol. In order to empower at-risk adolescents, prevention efforts are needed to promote protective factors and processes (Wong \& Lee, 2005).

\section{Study Habits}

Risko, Alvarez and Fairbank, (1991) indicated that students who achieved adopted strategies to monitor and manage their time for studying and success in course work reinforces the continued use of these strategies such as; time management, study environment, library use, memory and attention. Researchers also confirmed significant correlations between study habits and drinking outcomes (dePyssler, Williams, \& Windle, 2005) and a negative correlation between the consumption of marijuana and GPA of undergraduate students (Larrieu, 2004). Scheier, Botvin, Diaz and Griffin (1999) concluded that prevention programs for middle or junior and high school students should increase academic and social competence with skills such as study habits and academic support.

\section{The Present Study}

The background provided suggests that there is prevalence use of substance abuse among the adolescents in Barbados, which may be due to their exposure to risk factors such as drug availability, which was also similar to the research findings in some Western societies. Prior studies also indicated that psychological resilience, study habits and interest in 
school are crucial to adolescents' academic achievement, wellbeing, health and happiness yet, there are no empirical studies to verify how these academic variables collectively relate to adolescents' attitudes to substance abuse in Barbados where adolescents were found to be at risk of substance abuse by previous studies. There is urgent need therefore to conduct a study to find out if significant relationships exist among psychological resilience, interest in school, study habit and attitudes toward substance abuse with a view of intensifying these protective factors thereby enhancing the students' academic achievement and preventing substance abuse among the secondary school adolescents in Barbados.

This study therefore specifically aims at:

1) Examining the relationships among these academic related variables and attitudes toward substance abuse;

2) Finding out the extent to which the academic related variables will relatively and jointly predict attitudes toward substance abuse among the secondary school adolescents in Barbados.

\section{Methods}

\subsection{Participants}

The participants were 220 fourth, fifth and sixth form secondary school adolescents randomly selected from four public secondary schools from different parishes in Barbados. Their ages ranged from 13 to 18 years $(M=15.1, S D=1.10), 88$ males and 132 females.

\subsection{Measures}

The four instruments used to collect data were Attitudes toward Substance Abuse Questionnaire (ASAQ), Interest in School Scale (ISS), Psychological Resilience Scale (PRS) and Study Habit Scale (SHS). They all have two sections: Section A of ASAQ, ISS, PRS and SHS elicits basic information about the participants' sex, age, school and class, while Section B assesses the constructs being studied. Each of the scales have 10 items, five positively and five negatively worded.

1) Attitude to Substance Abuse Questionnaire (ASAQ): Section B assesses the students' attitude to substance abuse. Items included: "Drug taking injures health" "Drug taking is a form of relaxation".

2) Interest in School Scale (ISS): Section B assesses students' willingness to participate in schoolwork. Items included: "Coming to school is very interesting" "I don't enjoy listening to my teacher(s)".

3) Psychological Resilience Scale (PRS): Section B assesses the adolescent's inherent ability to cope with academic stress and life generally. Items included: "I am calm in stressful situations', 'When I am in a difficult situation, I don't usually find my way out of it".

4) Study Habit Scale (SHS) has two sections: Section B assesses the students' study skills and the strategies adopted in studying. Items included: 'I review each subject regularly during the term to cover the syllabus" "I don't concentrate when studying”.

All the items have the modified Likert format requiring the participants to rate their responses with corresponding scores; strongly agree 4 ; agree 3 ; disagree 2 ; strongly disagree 1 . The items were generated during literature review and the initial versions were given to experts for suggestions and comments before coming up with the final versions. The Cronbach alpha reliability coefficients of $0.71,0.73,0.78$ and 0.70 were obtained for ASAQ, ISS, PRS and SHS respectively.

\subsection{Procedure}

Informed consents for the students to participate in the survey were obtained from the school principals and their parents. The adolescents were surveyed in their school halls by the researcher with the assistance of the school principals, the teachers and the school guidance counselors. The researcher took time to brief the participants on the process of answering the items in the questionnaires and that the drugs being referred to in (ASAQ) are psychoactive drugs (drugs that alter thinking, perception, emotions, or consciousness). The students were told that the information would remain confidential and that they were free not to participate in the study if they so wished. The administration of the instruments lasted for approximately one hour.

\subsection{Data Analysis}

Descriptive Statistics, Pearson Product Moment Correlation and Stepwise Multiple Regressions were conducted to analyse the data. All the negatively worded items were reversed during analysis. 


\section{Results}

The first aim of this research was to find out the relationships between the academic related variables and attitudes toward substance abuse. The statistically significant negative correlations among the variables are presented in Table 1 . The three academic related variables (interest in school, psychological resilience and study habit) all negatively correlated with attitudes towards substance abuse signifying that lower scores on the academic related variables' scales and higher scores on the attitude scale were associated with adolescents' vulnerability to substance abuse. These implied that adolescents who are not interested in school, who are not resilient and who do not study effectively tended to have favourable attitudes toward substance abuse. There were also significant positive associations among the variables thus implying that adolescents who were intrinsically motivated to come to school will probably display the inherent ability to cope with academic stress which may likely help in developing good study habit necessary for academic achievement thus being less vulnerable to substance abuse.

$<$ Table 1 about here $>$

These relationships are also illustrated in Figures 1 and 2.

$<$ Figures $1 \& 2$ about here $>$

The second aim of this study was to estimate the relative contributions of the predictor variables to the variance in attitudes to substance abuse. Thus, stepwise regression analysis was computed with attitudes to substance abuse as the dependent measure and the academic related variables being the predictors as seen in Table 2. Interest in school was entered first to find out how much variability it could significantly account for, followed by psychological resilience to know if the amount of explained variability would significantly increase when included and lastly study habit was also added to see its significant relative contribution.

As can be seen in Table 2 Step 1, interest in school alone accounted for 37\% (R Square $=0.369$ ) of the variance in attitude to substance abuse, the inclusion of psychological resilience in Step 2 accounted for $43 \%$ (R square $=0.432$ ) which resulted in additional 6\% of the variance and lastly in Step 3, the inclusion of study habit accounted for $45 \%$ (R Square $=0.445$ ) which resulted in additional $2 \%$ of the variance in attitudes to substance abuse. In Step 3 also, the unstandardised $b$ and the standardised $\beta$ values reveal the decreasing order of the predictors: interest in school $>$ psychological resilience $>$ study habit showing that interest in school was the best predictor $(\beta=0.39, p<0.01)$, followed by psychological resilience $(\beta=0.21, \mathrm{p}<0.01)$ and study habit $(\beta=0.16, \mathrm{p}<0.01)$. Thus, each of the academic variables contributed significantly to adolescents' attitude to substance abuse with interest in school as the best predictor.

The final aim of this study was to find out the joint contributions of the academic variables. These predictors accounted for $45 \%$ (R Square $=0.445$ ) of the variance being accounted for in attitudes to substance abuse as seen in Table 2 . Using the stepwise method therefore, a significant model emerged, $(\mathrm{F}(3,216)=57.63, \mathrm{p}<.0005)$. The model explains $45 \%$ of the variance in attitude to substance abuse ( $\mathrm{R}$ square $=0.445$ ), therefore adolescents' vulnerability to substance abuse is significantly predicted by interest in school, psychological resilience and study habit.

\section{$<$ Table 2 about here $>$}

\section{Discussion}

This study investigated the relationships between the academic related variables (interest in school, psychological resilience, and study habit) and attitudes toward substance abuse among the secondary school adolescent Barbadian sample. The result indicated that the sample of this study is vulnerable, $63 \%$ scored high in the attitude scale. This may be due to their exposure to some risk factors as earlier found in a survey of secondary school adolescents in Barbados (National Council on Substance Abuse 2006).

One of the major findings of this study is that significant negative associations exist between the variables (interest in school, psychological resilience, study habit) and the students' attitudes toward substance abuse. This is quite expected and a probable reason for this finding among this Barbadian sample could be attributed to the fact that some of the participants came from two top schools in Barbados where there are clusters of intelligent students who probably were intrinsically motivated, able to cope with academic stress and study effectively. These findings lend credence to the National Household Survey on Drug (2003) report that the United States adolescents who felt that the things they learned in school were meaningful attend school and were less likely to have used illicit drugs and that poor school satisfaction was significantly associated with cannabis use among Danish adolescents (Hoff et al., 2010). Additionally, (Karatzias, et al. 2001) fond that school stress most accurately predicted Scottish student's likelihood to try alcohol and that significant negative correlations exist between a sample of African American College students' study habits and drinking outcomes (dePtssler et al. 2005). 
Another major finding of this study is that each of the academic variables (interest in school, psychological resilience and study habit) significantly contributed to the variance in attitude to substance and interestingly, interest in school has the highest contribution, followed by psychological resilience and lastly study habit. This looks logical, the reason being that interest is foremost in all activities. A probable reason may also be that these academic related variables are all protective factors which are essential for substance abuse prevention hence their significant and relative contributions to the total variance being accounted for in attitudes to substance abuse. This result confirmed the earlier literature findings that the protective factors have reduced potential for substance abuse while the risk factors have greater potential for substance abuse and that the more the risks a child is exposed to, the more likely the child will abuse drugs (Dishion et al.2002; Fayombo 1999; National Institute on Drug Abuse 2008). Although, this Barbadian sample demonstrated interest in academic work, ability to study effectively and withstand academic stress with interest in school being most significant but they also seemed to be favourably disposed to substance abuse which may be attributed to Gogtay et al. (2004) report that the brain areas, (prefrontal cortex) for assessing situations, making sound decisions and keeping the emotions and desires under control are still maturing during adolescence thereby putting them at increased risk for poor decisions.

The final result is that the variables jointly contributed $45 \%$ of the total variance in students' attitudes to substance abuse and this was significant which evident that the model that emerged is fit and it has the ability to predict adolescents' attitude to substance abuse $(F(3,216)=57.63, \mathrm{p}<.0005)$. These academic related variables which are indices of students' academic achievement, are protective factors of substance abuse. Hence, the significant prediction among this Barbadian sample who had been provided quality education by the Barbados Government from childhood stage. Contrarily, their favourable attitude to substance abuse may be attributed to the fact that in the Caribbean, young males regarded drinking alcohol and ganja smoking as a "rite of passage" rather than substance abuse (Caribbean Research Crucial to tackling Regional Drug Abuse 2005).

\section{Conclusion}

The findings of this study can be useful in designing substance abuse prevention programmes for the adolescents to subdue its escalation especially among those prone to substance abuse as found among the sample of this study. This will require the combined efforts of the psychologists, educators, school guidance councellors, parents and the community leaders to intensify the protective factors of substance abuse such as interest in school, psychological resilience and study habit that are indices of academic achievement in order to counter the risk factors such as academic failure, which may likely expose the adolescents to substance abuse.

One of the limitations of this study is that the researcher was able to study three out of the myriads of academic related variables, the reason being that it is not possible to accommodate all of them in one study. Further studies can investigate the relationships of other related variables such as peer relationships, parental control and social skills on adolescents' attitudes to substance abuse to further expand literature on substance abuse prevention. In spite of this limitation, this study uniquely contributes to the relevant literature by identifying interest in school, psychological resilience and study habit as significantly, relatively and jointly predicting attitudes to substance abuse with interest in school being the best predictor while psychological resilience and study habit were other significant predictors among the secondary school adolescents in Barbados.

\section{References}

Aarons, G.A., Brown, S. A., Hough, R. L., Garland, A. F., \& Wood, P. A. (2001). Prevalence of adolescent substance use disorders across five sectors of care. Journal of the American Academy of Child and Adolescent Psychiatry, 40, 419-464. doi:10.1097/00004583-200104000-00010, http://dx.doi.org/10.1097/00004583-200104000-00010

Bauer, A.M., Keefe, C.H. \& Shea, T.M. (2001). Students with learning disabilities or emotional/behavioral disorders, New Jersey: Merrill Prentice Hall.

Blum, R.W., \& Ireland, M. (2004). Reducing Risk, Increasing Protective Factors: Findings from the Caribbean Youth Health Survey. Journal of Adolescent Health, 35, 493-500.

Caribbean Research Crucial to Tackling Regional Drug Abuse. (CARICOM) (2005) Retrieved on 20 July 2010 from: http://www.caricom.org/jsp/pressreleases/pres178_05.jsp

dePyssler, B., Williams, V. S .L., \& Windle, M. (2005). Alcohol consumption and positive study practices among African American college students. Journal of Alcohol \& Drug Education, 49(4), $26-44$.

Dishion, T., Kavanagh, K., Schneiger, A.K.J., Nelson, S., \& Kaufman, N. (2002). Preventing early adolescent substance 
use: A family centered strategy for the public middle school. Prevention Science, 3(3), $191-202$. doi:10.1023/A:1019994500301, http://dx.doi.org/10.1023/A:1019994500301

Donald, D., Lazarus, S., \& Lolwana, P. (2002). Educational Psychology in Social Context, Cape Town: Oxford University Press.

Douglas K.G., \& Fountain T. (2004) Findings from drug use surveys of Caribbean students, West Indian Medical Journal, 253, 52-62.

Fayombo, G.A. (1999) The Efficacy of Social Skills Training in changing the attitudes of some adolescents in Ibadan toward Substance Abuse. The Counsellor: Journal of Counselling Association of Nigeria (CASSON) 17(1), 36 - 42.

Gogtay, N., Giedd, J. N., Lusk, L., Hayashi, K. M., Greenstein, D., Vaituzis, A. C., Nugent, T. M., Herman, D. H., Clasen, L. S., Toga, A. W., Rapoport, J. L., \& Thompson, P. M. (2004). Dynamic mapping of human cortical development during childhood through early adulthood. The National Academy of Sciences, 101(21), 8174-8179. doi:10.1073/pnas.0402680101, http://dx.doi.org/10.1073/pnas.0402680101

Goleman, D. (2006) Working with Emotional Intelligence, Bantam Dell: New York.

Hoff, D. A., Andersen, A., \& Holstein, B. E. (2010). Poor school satisfaction and number of cannabis using peers within school classes as individual risk factors for cannabis use among adolescents. School Psychology International, 31, 547-556. doi:1177/0143034310382870, http://spi.sagepub.com/content/31/5/547.full.pdf+html

Karatzias, A., Power, K. G. \& Swanson, V. (2001). 'Predicting use and maintenance of use of Substances in Scottish adolescents. Journal of Youth and Adolescence, 30, 465-484. doi:10.1023/A:1010497216920, http://dx.doi.org/10.1023/A:1010497216920

Kurtz S., Douglas K. G., \& Lugo Y. (2005). Sexual risks and concerns about AIDS among adolescents in Anguilla. AIDS Care. 17, 36-44. doi:10.1080/09540120500121250, http://dx.doi.org/10.1080/09540120500121250

Larrieu, F. R. (2004). The Relationship between marijuana and alcohol use and academic performance in undergraduate students, Undergraduate Research, Department of Psychology. Available online at http://www.webclearinghouse.net/volume/.Retrieved 17 July, 2010

Luo, Q., Urberg, K. A., \& Fang, X. (1999). Influence of peers, parents and individual characteristics on adolescent drug use in two cultures, Merrill-Palmer Quarterly, 45, Available at http://www.questia.com/googleScholar.qst?docId=5001896286 Retrieved April 2, 2011

Maharaj, R. G., Nunes, P., \& Renwick, S. (2009). Health risk behaviours among adolescents in The English-Speaking Caribbean. Child Adolescent Psychiatry Mental Health 3(10), doi: 10.1186/1753-2000-3-10. Retrieved from http://www.capmh.com/content/3/1/10

Moore, G. F., Rothwell, H., \& Segrott, J. (2010) An exploratory study of the relationship between parental attitudes and behaviour and young people's consumption of alcohol. Substance Abuse Treatment, Prevention and Policy, 5(6), 6-16. doi:10.1186/1747-597X-5-6, http://dx.doi.org/10.1186/1747-597X-5-6

National Council for Substance Abuse (NCSA) (2006) Secondary School Students Survey in Barbados. Retrieved from http:/www.ncsa.org.bb/images/stories/research/BARBADOS\%20SECONDARY\%20SCHOOL\%20SURVEY\%20 2006\%20final.pdf on 19 March 2010

National Household Survey on Drug Abuse Report (NHSDA) (2003). School experiences and substance use among youths. Retrieved on 20 July 2010 from http://www.oas.samhsa.gov/2k3/school/school.htm

National Institute on Drug Abuse (NIDA) (2003). Preventing Substance Abuse among Children and Adolescents: Risk Factors and Protective Factors Retrieved on July 20, 2010 from http://www.nida.nih.gov/prevention/risk.html.

National Survey on Drug Use \& Health (2009) Report on Adolescents'substance abuse prevention, addiction treatment, and mental health services in the United States. Retrieved from http://www.oas.samhsa.gov/nsduhLatest.htm on 2 April, 2011

Olatoye, R.A., \& Ogunkola, B.J. (2008). Parental involvement, interest in schooling and science achievement of junior secondary school students in Ogun State, Nigeria, College Teaching Methods \& Styles Journal 4(8), 33-40.

Risko, V.J., Alvarez, M.C., \& Fairbank, M.M. (1991). External factors that influence study. In R.F Flippo and D.C Caverly (Eds.), Teaching, reading and study strategies at college level 195-236 Navark, DE: International Reading Association. 
Scheier, L., Botvin, G., Diaz, T. \& Griffin, K. (1999). Social skills, competence, and drug refusal efficacy as predictors of adolescent alcohol use. Journal of Drug Education 29(3), 251-278.

Subramaniam, G.A., S Stitzer, M.A., Woody, G., Fishman, M. J., and Kolodner, K. (2009).

Clinical characteristics of treatment seeking adolescents with opioid versus cannabis/alcohol use disorders. Drug Alcohol Dependent, 99(1-3), 141-149. doi:10.1016/j.drugalcdep.2008.07.016, http://dx.doi.org/10.1016/j.drugalcdep.2008.07.016

Vaughn, M. G., Ollie,M. T., McMillen,.J. C., Scott, L., \& Munson, M., (2007). Substance use and abuse among older youth in foster care. Addictive Behaviour 32(9), 1929-1935. doi:10.1016/j.addbeh.2006.12.012, http://dx.doi.org/10.1016/j.addbeh.2006.12.012

Wong, K., \& Lee, T. (2005). Professional discourse among social workers working with at-risk adolescents in Hong Kong. In: Ungar M (ed.). Handbook for Working with Children and Youth; Pathways to Resilience across Cultures and Contexts,. California: Sage Publications. Pp 313-327

Zoccolillo, M., Vitaro, F., \& Tremblay, R. E. (1999). Problem of drug and alcohol use in a community sample of adolescents. Journal of the American Academy of Child and Adolescent Psychiatry, 38(7), 900-907. doi:10.1097/00004583-199907000-00021, http://dx.doi.org/10.1097/00004583-199907000-00021

Table 1. Correlation Matrix of interest in school, psychological resilience, study habit and attitudes toward substance abuse

\begin{tabular}{|l|c|c|c|c|}
\hline Variables & $\begin{array}{l}\text { Attitude to } \\
\text { Substance Abuse }\end{array}$ & Interest in School & $\begin{array}{l}\text { Psychological } \\
\text { Resilience }\end{array}$ & Study Habit \\
\hline $\begin{array}{l}\text { Attitudes to } \\
\text { Substance Abuse }\end{array}$ & - & - & & \\
\hline Interest in School & $-0.607^{* *}$ & $0.643^{* *}$ & - & \\
\hline $\begin{array}{l}\text { Psychological } \\
\text { Resilience }\end{array}$ & $-0.583^{* *}$ & $0.485^{* *}$ & $0.724^{* *}$ & - \\
\hline Study Habit & $-0.508^{* *}$ & & \\
\hline
\end{tabular}

**Significant $\quad(p<0.01)$

These relationships are also illustrated in Figures 1 and 2.

Table 2. Stepwise regression analysis predicting adolescents' attitudes toward substance abuse

\begin{tabular}{|l|l|c|c|c|c|}
\hline & Predictors & $b$ & $S E b$ & $\beta$ & $\Delta R^{2}$ \\
\hline Step 1 & Interest in School & -0.56 & 0.05 & $-0.61^{* *}$ & $0.37^{* *}$ \\
\hline \multirow{2}{*}{ Step 2 } & Interest in School & -0.37 & 0.06 & $-0.40^{* *}$ & \\
& Psychological Resilience & -0.42 & 0.09 & $-0.33^{* *}$ & $0.06^{* *}$ \\
\hline \multirow{3}{*}{ Step 3 } & Interest in School & -0.36 & 0.06 & $-0.39^{* *}$ & \\
& Psychological Resilience & -0.27 & 0.11 & $-0.21^{* *}$ & \\
& Study Habit & -0.26 & 0.12 & $-0.16^{*}$ & $0.02^{*}$ \\
\hline
\end{tabular}

${ }^{* *} \mathrm{p}<0.05$ in steps $1 \& 2,{ }^{*} \mathrm{p}<0.05$ in step 3 


\section{Relationships between Academic Related Variables and Attitude to Substance Abuse}

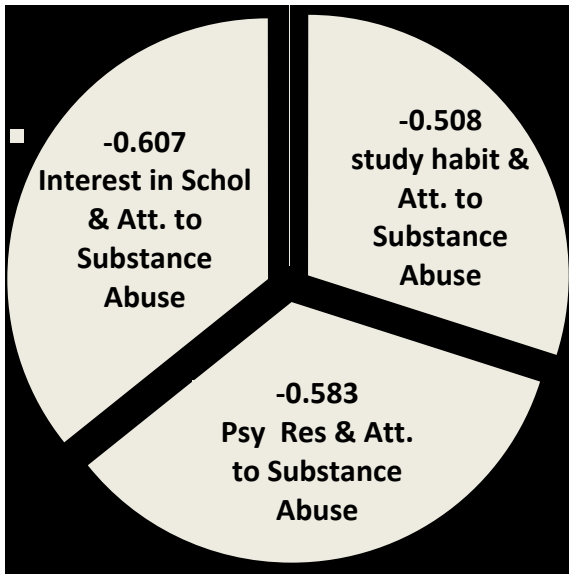

Figure 1. Relationships among interest in school, psychological resilience, study habit and attitudes to substance abuse

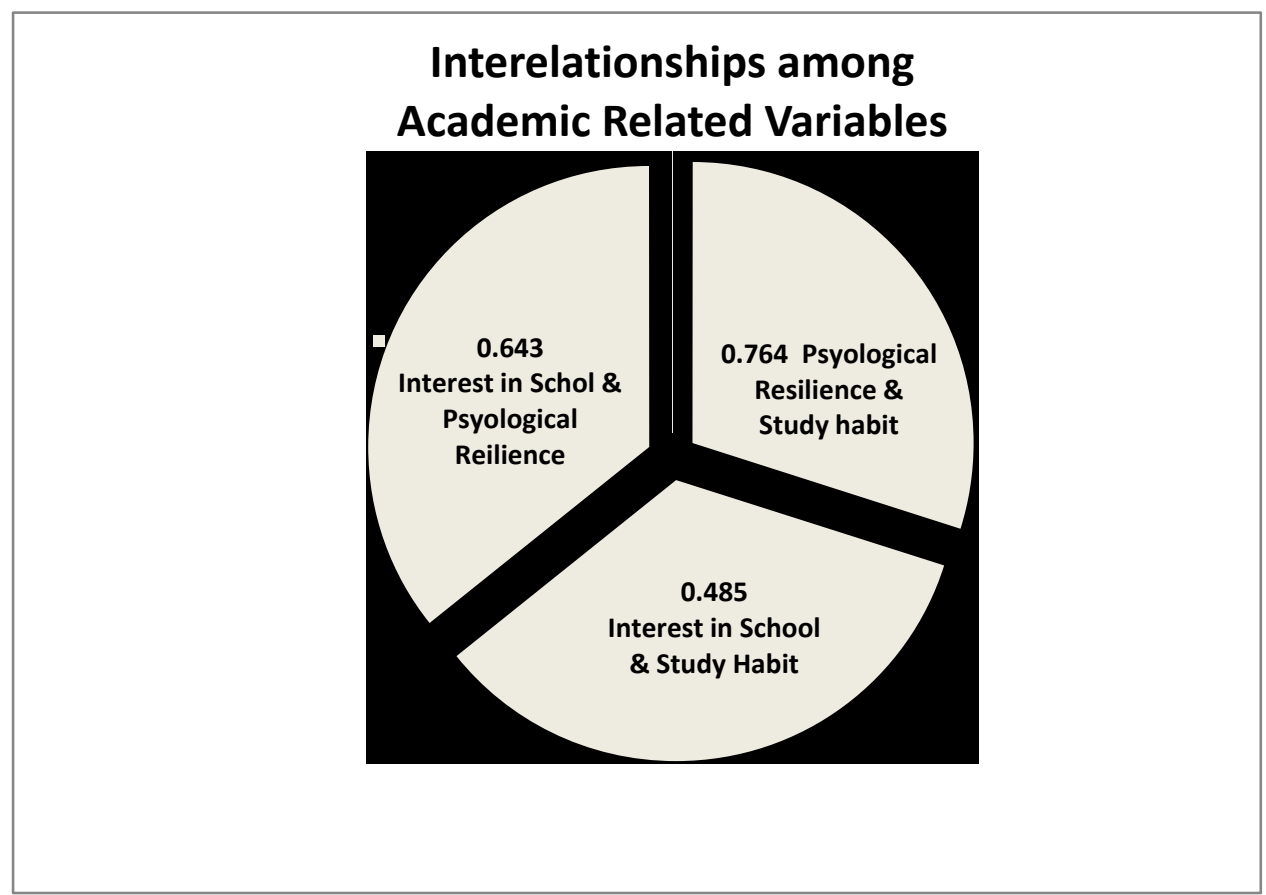

Figure 2. Interrelationships among the academic variables 